\title{
Mechanism linking diabetes mellitus and obesity
}

This article was published in the following Dove Press journal:

Diabetes, Metabolic Syndrome and Obesity:Targets and Therapy

4 December 2014

Number of times this article has been viewed

\section{Abdullah S Al-Goblan' \\ Mohammed A Al-Alfi \\ Muhammad Z Khan ${ }^{2}$ \\ 'Diabetes Center, King Fahad Specialist Hospital, Buraidah, \\ Qassim, Kingdom of Saudi Arabia; \\ ${ }^{2}$ Sulaiman AIRajhi Colleges, \\ Al Bukairiyah, Kingdom \\ of Saudi Arabia}

\section{Video abstract}

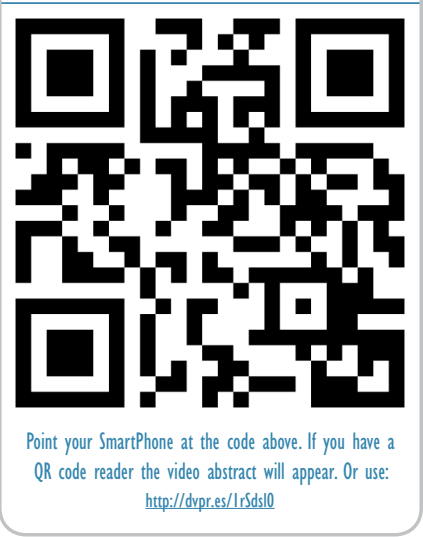

Correspondence: Abdullah S Al-Goblan Diabetes Center, King Fahad Specialist Hospital, Buraidah, Qassim, PO Box 2290, Buraidah 81999, Kingdom of Saudi Arabia Fax +966063250870

Email agoblan@yahoo.com
Abstract: Body mass index has a strong relationship to diabetes and insulin resistance. In obese individuals, the amount of nonesterified fatty acids, glycerol, hormones, cytokines, proinflammatory markers, and other substances that are involved in the development of insulin resistance, is increased. The pathogenesis in the development of diabetes is based on the fact that the $\beta$-islet cells of the pancreas are impaired, causing a lack of control of blood glucose. The development of diabetes becomes more inevitable if the failure of $\beta$-islet cells of the pancreas is accompanied by insulin resistance. Weight gain and body mass are central to the formation and rising incidence of type 1 and type 2 diabetes. This literature review will demonstrate the facts that link obesity with insulin resistance and pancreatic $\beta$-cell dysfunction. In conclusion, new approaches in managing and preventing diabetes in obese individuals must be studied and investigated based on the facts.

Keywords: diabetes mellitus, obesity, insulin resistance

\section{Introduction}

Diabetes mellitus (DM) is a chronic disorder that can alter carbohydrate, protein, and fat metabolism. It is caused by the absence of insulin secretion due to either the progressive or marked inability of the $\beta$-Langerhans islet cells of the pancreas to produce insulin, or due to defects in insulin uptake in the peripheral tissue. DM is broadly classified under two categories, which include type 1 and type 2 diabetes. ${ }^{1}$

Type 1 diabetes occurs most commonly in children, but it can sometimes also appear in adult age groups, particularly in those in their late thirties and early forties. Patients with type 1 diabetes are generally not obese and frequently present with an emergency status known as diabetes ketoacidosis. ${ }^{2}$

The etiology of type 1 diabetes can be explained by damage to the pancreatic cells due to environmental or infectious agents. In individuals who are susceptible to genetic alterations, the immune system is triggered to produce an immune response against altered $\beta$-cells, or against molecules in $\beta$-cells that are similar to viral proteins. ${ }^{3}$ Approximately $80 \%$ of patients with type 1 diabetes show circulating islet cell antibodies, and most of these patients have anti-insulin antibodies before receiving insulin therapy. ${ }^{4}$

The major factor in the pathophysiology of type 1 diabetes is considered to be autoimmunity. ${ }^{5}$ There is a strong relationship between type 1 diabetes and other autoimmune diseases such as Graves' disease, Hashimoto's thyroiditis, and Addison's disease. When these diseases are present, the prevalence rates of type 1 diabetes increase. ${ }^{6}$

Vitamin D plays a major role in the pathogenesis and prevention of type 1 diabetes, as recent evidence suggests. ${ }^{5}$ In addition, vitamin D deficiency is an independent predictor 
of the development of coronary artery disease in individuals with type 1 diabetes. Furthermore, another study has proved that vitamin $\mathrm{D}$ deficiency in type 1 diabetes may predict all causes of mortality. ${ }^{7}$

Type 2 diabetes has a different pathophysiology and etiology as compared to type 1 diabetes. The existence of many new factors - for example, the increased prevalence of obesity among all age groups and both sex physical inactivity, poor diet, and urbanization - means that the number of patients diagnosed with type 2 diabetes is rising. ${ }^{8}$ This finding is significant because it will allow health planners to make rational plans and reallocate health resources accordingly. ${ }^{9}$

Type 2 diabetes is described as a combination of low amounts of insulin production from pancreatic $\beta$-cells and peripheral insulin resistance. ${ }^{10}$ Insulin resistance leads to elevated fatty acids in the plasma, causing decreased glucose transport into the muscle cells, as well as increased fat breakdown, subsequently leading to elevated hepatic glucose production. Insulin resistance and pancreatic $\beta$-cell dysfunction must occur simultaneously for type 2 diabetes to develop. Anyone who is overweight and/or obese has some kind of insulin resistance, but diabetes only develops in those individuals who lack sufficient insulin secretion to match the degree of insulin resistance. Insulin in those people may be high, yet it is not enough to normalize the level of glycemia. ${ }^{11}$

Dysfunction of $\beta$-cells is a main factor across the progression from prediabetes to diabetes. After the progression from normal glucose tolerance to abnormal glucose tolerance, postprandial blood glucose levels increase initially. Thereafter, fasting hyperglycemia may develop as the suppression of hepatic gluconeogenesis fails. ${ }^{12}$ Despite the fact that the pathophysiology of diabetes differs between type 1 and type 2 diabetes, most of the complications are similar, which may include macrovascular and microvascular complications. ${ }^{13}$ Abnormal glycemia appears to contribute to microvascular and metabolic complications. However, macrovascular complications appear to be unrelated to glycemic abnormalities. Insulin resistance with lipid abnormalities (ie, low levels of high-density lipoprotein, and high levels of low-density lipoprotein and triglycerides), thrombotic abnormalities, as well as atherosclerotic risk factors (for example, smoking, family history, and hypertension) determine the cardiovascular risk in a patient. Cardiovascular risk is associated with the development of insulin resistance even before frank hyperglycemia exists. A hypothesis of complications called the "ticking clock" developed by Haffner et al in 1999 showed that the onset of hyperglycemia puts one at risk for developing macrovascular complications at an earlier point, perhaps at the onset of insulin resistance and before hyperglycemia. ${ }^{14}$

\section{Obesity}

Overweight and obesity are defined by an excess accumulation of adipose tissue to an extent that impairs both physical and psychosocial health and well-being. ${ }^{15}$ Obesity is considered a health disaster in both developed and developing countries. $^{16}$

The prevalence is escalating significantly in many nations worldwide. This pandemic needs to be stopped if the economic costs, social hazards, morbidity, and mortality of the disease are considered.

\section{Obesity and type I diabetes}

The rising incidence of type 2 diabetes among children and adults is related to the epidemic of obesity. A similar etiology is also responsible for a similar increase in type 1 diabetes. ${ }^{17}$ While the underling pathophysiology of type 1 diabetes, which is autoimmune in nature, continues to be investigated and studied, the exact mechanism causing the rise in the incidence of type 1 diabetes remains unclear, particularly in young age groups. The DIAMOND (Diabetes Mondiale) study, ${ }^{18}$ which collected data on childhood diabetes from 112 centers around the world, demonstrated an approximate $2.8 \%$ annual increase in type 1 diabetes over the period from 1989-2000.

The etiology of type 1 diabetes, according to twin studies, indicates a joint contribution of environmental and genetic factors. ${ }^{8}$ Furthermore, the importance of environmental factors in the etiology of diabetes is indicated by a significant rise in type 1 diabetes incidence in immigrants from lower to higher incidence regions. Multiple triggers for the development of type 1 diabetes have been investigated, including short-duration or the absence of breastfeeding, exposure to cow's milk protein, and exposure to some kind of infection such as enterovirus or rubella. However, none of these triggering factors has been shown to be the definitive cause. $^{19}$

The association between type 1 diabetes and weight gain was first investigated by Baum et $\mathrm{al}^{20}$ in 1975. The Baum et al study suggested that there was an association related to overfeeding or to hormonal dysregulation. ${ }^{20}$

The "accelerator hypothesis" proposed by Wilkin ${ }^{21}$ is considered one of the most accepted theories that demonstrates the association between body mass and type 1 diabetes. The authors of this theory suggested that increasing body weight in young age groups increases the risk of developing type 1 
diabetes. There is an inverse relationship between body mass index and age at diagnosis. Furthermore, as young children gain more weight, diabetes can be diagnosed earlier. This is explained by the fact that more weight accelerates insulin resistance, leading to the development of type 1 diabetes in individuals who are predisposed genetically to diabetes. Following this study, many papers were published supporting Wilkin's accelerator hypotheses. One study conducted in the United States in 2003 showed a significant increase in the prevalence of being overweight in children with type 1 diabetes, from $12.6 \%$ in the period $1979-1989$ to $36.8 \%$ in the period 1990-1998. To date, the exact mechanism and relationship between type 1 diabetes and obesity remains inconclusive and needs further explanation. ${ }^{21}$

\section{Obesity and type 2 diabetes}

The increased prevalence of obesity these days has drawn attention to the worldwide significance of this problem. ${ }^{17}$ In the US, approximately two-thirds of the adult population is considered to be overweight or obese. Similar trends are being noticed worldwide. ${ }^{22}$ Obesity is linked to many medical, psychological, and social conditions, the most devastating of which may be type 2 diabetes. At the start of this century, 171 million people were estimated to have type 2 diabetes, and this figure is expected to increase to 360 million by $2030 .^{23}$

Both type 2 diabetes and obesity are associated with insulin resistance. Most obese individuals, despite being insulin resistant, do not develop hyperglycemia. Pancreatic $\beta$-cells of the islet of Langerhans release adequate amounts of insulin that are sufficient to overcome insulin level reductions under normal circumstances, thus maintaining normal glucose tolerance. ${ }^{11}$

Throughout the natural history of type 2 diabetes, endothelial dysfunction is accompanied with obesity/ insulin resistance in diabetes and prediabetes conditions (this includes people with impaired glucose tolerance and/or impaired fasting glucose). In order to develop insulin resistance and obesity, thereby causing type 2 diabetes, $\beta$-cells should not be able to compensate fully for decreased insulin sensitivity. The nonesterified fatty acids (NEFAs) that are secreted from adipose tissue in obese people may lead to the hypothesis that insulin resistance and $\beta$-cell dysfunction are most likely linked. ${ }^{24}$

\section{Obesity and insulin resistance}

Insulin sensitivity fluctuation occurs across the natural life cycle. For example, insulin resistance is noticed during puberty, in pregnancy, and during the aging process. ${ }^{25}$ In addition, lifestyle variations, such as increased carbohydrate intake and increased physical activity, are associated with insulin sensitivity fluctuations. ${ }^{10}$ Obesity is considered the most important factor in the development of metabolic diseases. Adipose tissue affects metabolism by secreting hormones, glycerol, and other substances including leptin, cytokines, adiponectin, and proinflammatory substances, and by releasing NEFAs. In obese individuals, the secretion of these substances will be increased. ${ }^{25}$

The cornerstone factor affecting insulin insensitivity is the release of NEFAs. Increased release of NEFAs is observed in type 2 diabetes and in obesity, and it is associated with insulin resistance in both conditions. ${ }^{26}$ Shortly after an acute increase of plasma NEFA levels in humans, insulin resistance starts to develop. Conversely, when the level of plasma NEFA decreases, as in the case with antilipolytic agent use, peripheral insulin uptake and glucose monitoring will be improved. ${ }^{27}$

Insulin sensitivity is determined by another critical factor, which is body fat distribution. Insulin resistance is associated with body mass index at any degree of weight gain. Insulin sensitivity also differs completely in lean individuals because of differences in body fat distribution. Individuals whose fat distribution is more peripheral have more insulin sensitivity than do individuals whose fat distribution is more central (ie, in the abdomen and chest area). ${ }^{25}$

Differences in adipose tissue distribution help explain, to some extent, how the metabolic effects of subcutaneous and intra-abdominal fat differ. Intra-abdominal fat is more related to the genes that secrete proteins and the specific types of proteins responsible for the production of energy. Adiponectin secretion by omental adipocytes is larger than the amount secreted by subcutaneous-derived adipocytes. Moreover, the quantity secreted from these omental adipocytes is negatively associated with increased body weight. ${ }^{26}$ The secretion of NEFAs to different tissue may be affected by their source.

Furthermore, abdominal fat is considered more lipolytic than subcutaneous fat, and it also does not respond easily to the antilipolytic action of insulin, which makes intraabdominal fat more important in causing insulin resistance, and thus diabetes..$^{27,28}$

Marcial et $\mathrm{al}^{29}$ further explained the molecular mechanisms of insulin resistance, inflammation, and the development of diabetes. One of the mechanisms of insulin is its effect as an anabolic hormone that enhances glycogen synthesis in liver and muscle. This in turn augments protein 
synthesis inhibiting the process of proteolysis. Insulin resistance is indeed an important factor in disease process. Fat storage and mobilization are other important factors causing insulin resistance.

\section{Obesity and $\beta$-cell dysfunction}

$\beta$-cells play a vital role in regulating insulin release, despite their fragility. The quantity of insulin released by $\beta$-cells fluctuates and changes according to the quantity, nature, and route of administration of the stimulus. Therefore, $\beta$-cells play a very important role in ensuring that in healthy subjects, concentrations of blood glucose are stable within a relatively normal physiological range. In obesity, insulin sensitivity, as well as the modulation of $\beta$-cell function, decreases. ${ }^{30}$

Insulin-resistant individuals, whether slim or fat, have more insulin responses and lower hepatic insulin clearance than those who are insulin sensitive. In a normal healthy subject, there is a continuous feedback relationship between the $\beta$-cells and the insulin-sensitive tissues. ${ }^{10}$ If the adipose tissue, liver, and muscles demand glucose, this will lead to increased insulin supply by the $\beta$-cells. If the glucose levels require stability, changes in insulin sensitivity must be matched by a relatively opposite change in circulating insulin levels. Failure of this process to take place results in a deregulation of glucose levels and the development of DM. If the $\beta$-cells are healthy, there is an adaptive response to insulin resistance, which leads to the maintenance of normal levels of glucose. By contrast, when pancreatic $\beta$-cells are impaired, abnormal glucose tolerance or abnormal fasting glucose may develop, and it may even be followed by the development of type 2 diabetes. ${ }^{30}$

A continued decline in $\beta$-cell function is one of the main causes leading to type 2 diabetes. According to literature, when $\beta$-cell dysfunction causes inadequate insulin secretion, fasting blood glucose and postprandial blood glucose will elevate. ${ }^{31}$ Subsequently, the decreased efficiency of hepatic and muscle glucose uptake will occur, with the absence or incomplete inhibition of liver glucose production. Further increases in blood glucose levels will lead to disease severity through glucotoxic effects on the pancreatic $\beta$-cells and negative effects on insulin uptake and peripheral tissue sensitivity. ${ }^{31}$

Conversely, in healthy subjects, elevating their blood glucose levels for 20 hours or more has an absolutely inverse action, because it will lead to enhanced $\beta$-cell function capacity and improve peripheral insulin uptake. ${ }^{16}$ These facts explain that a genetic risk factor is necessary for the occurrence of $\beta$-cell function impairment. The progression of time, as well as a pre-existing genetic abnormality in insulin secretion and a subsequently continuous elevation of blood glucose levels, lead to complete $\beta$-cell failure. ${ }^{24}$

A second factor that might contribute to a continuous loss of function of $\beta$-cells is increasing plasma NEFA levels. Despite the fact that NEFAs play a major role in insulin release, the continuous exposure to NEFAs is related to significant malfunction in glucose-stimulated insulin secretion pathways and reduced insulin biosynthesis. Moreover, the occurrence of insulin resistance in vivo and a failure of the compensatory mechanism of $\beta$-cells in humans contributes to increase amounts of NEFA levels produced by lipids. ${ }^{32}$

The two actions of NEFA contribute to a significant etiology that links $\beta$-cell dysfunction and insulin resistance in people with type 2 diabetes, and those who are at risk for the disease. The effect of lipotoxic increases in plasma NEFA levels and the rise of glucose levels might produce a more harmful effect known as glucolipotoxicity. ${ }^{33,34}$

\section{Conclusion}

Diabetes and obesity are chronic disorders that are on the rise worldwide. Body mass index has a strong relationship to diabetes and insulin resistance. In an obese individual, the amount of NEFA, glycerol, hormones, cytokines, proinflammatory substances, and other substances that are involved in the development of insulin resistance are increased. Insulin resistance with impairment of $\beta$-cell function leads to the development of diabetes. Gaining weight in early life is associated with the development of type 1 diabetes. NEFA is a cornerstone in the development of insulin resistance and in the impairment of $\beta$-cell function. New approaches in managing and preventing diabetes in obese individuals must be studied and investigated based on these facts.

\section{Disclosure}

The authors report no conflicts of interest in this work.

\section{References}

1. Scheen AJ. Pathophysiology of type 2 diabetes. Acta Clin Belg. 2003;58(6):335-341.

2. American Diabetes Association. Diagnosis and classification of diabetes mellitus. Diabetes Care. 2007;30 Suppl 1:S42-S47.

3. Hutton JC, Davidson HW. Cytokine-induced dicing and splicing in the $\beta$-Cell and the immune response in Type 1 Diabetes. Diabetes. 2010;59(2):335-336.

4. van Belle TL, Coppieters KT, von Herrath MG. Type 1 diabetes: etiology, immunology, and therapeutic strategies. Physiol Rev. 2011;91(1):79-118.

5. Mathieu C, Badenhoop K. Vitamin D and type 1 diabetes mellitus: state of the art. Trends Endocrinol Metab. 2005;16(6):261-266.

6. Philippe MF, Benabadji S, Barbot-Trystram L, Vadrot D, Boitard C, Larger E. Pancreatic volume and endocrine and exocrine functions in patients with diabetes. Pancreas. 2011;40(3):359-363. 
7. Joergensen C, Hovind P, Schmedes A, Parving HH, Rossing P. Vitamin D levels, microvascular complications, and mortality in type 1 diabetes. Diabetes Care. 2011;34(5):1081-1085.

8. Ershow AG. Environmental influences on development of type 2 diabetes and obesity: challenges in personalizing prevention and management. J Diabetes Sci Technol. 2009;3(4):727-734.

9. Wild S, Roglic G, Green A, Sicree R, King H. Global prevalence of diabetes: estimates for the year 2000 and projections for 2030. Diabetes Care. 2004;27(5):1047-1053.

10. Kasuga M. Insulin resistance and pancreatic $\beta$ cell failure. J Clin Invest. 2006;116(7):1756-1760.

11. Røder ME, Porte D, Schwartz RS, Kahn SE. Disproportionately elevated proinsulin levels reflect the degree of impaired B cell secretory capacity in patients with noninsulin-dependent diabetes mellitus. J Clin Endocrinol Metab. 1998;83(2):604-608

12. Porte D Jr. Banting lecture 1990. Beta-cells in type II diabetes mellitus. Diabetes. 1991;40(2):166-180.

13. Fowler MJ. Microvascular and Macrovascular Complications of Diabetes. Clinical Diabetes. 2008;26(2):77-82.

14. Haffner SM, D’Agostino R, Mykkänen L, et al. Insulin sensitivity in subjects with type 2 diabetes. Relationship to cardiovascular risk factors: the Insulin Resistance Atherosclerosis Study. Diabetes Care. 1999;22(4):562-568.

15. Naser KA, Gruber A, Thomson GA. The emerging pandemic of obesity and diabetes: are we doing enough to prevent a disaster? Int J Clin Pract. 2006;60(9):1093-1097.

16. Gallagher D, Heymsfield SB, Heo M, Jebb SA, Murgatroyd PR, Sakamoto Y. Healthy percentage body fat ranges: an approach for developing guidelines based on body mass index. Am J Clin Nutr. 2000;72(3):694-701.

17. Arora S. Molecular basis of insulin resistance and its relation to metabolic syndrome. In: Insulin Resistance. Rijeka, Croatia: InTech Europe; 2012. Available from: http://www.intechopen.com/books/insulinresistance/molecular-basis-of-insulin-resistance-and-its-relation-tometabolic-syndrome. Accessed September 26, 2014

18. DIAMOND Project Group. Incidence and trends of childhood type 1 diabetes worldwide 1990-1999. Diabet Med. 2006;23(8):857-866.

19. Harder T, Roepke K, Diller N, Stechling Y, Dudenhausen JW, Plagemann A. Birth weight, early weight gain, and subsequent risk of type 1 diabetes: systematic review and meta-analysis. Am J Epidemiol. 2009;169(12):1428-1436.

20. Baum JD, Ounsted M, Smith MA. Letter: Weight gain in infancy and subsequent development of diabetes mellitus in childhood. Lancet. 1975;2(7940):866

21. Wilkin TJ. The accelerator hypothesis: weight gain as the missing link between type I and type II diabetes. Diabetologia. 2001;44(7):914-922.

22. Tsai AG, Williamson DF, Glick HA. Direct medical cost of overweight and obesity in the USA: a quantitative systematic review. Obes Rev. 2011;12(1):50-61.
23. McKeigue PM, Shah B, Marmot MG. Relation of central obesity and insulin resistance with high diabetes prevalence and cardiovascular risk in South Asians. Lancet. 1991;337(8738):382-386.

24. Kahn SE, Hull RL, Utzschneider KM. Mechanisms linking obesity to insulin resistance and type 2 diabetes. Nature. 2006;444(7121): $840-846$.

25. KarpeF, Dickmann JR, Frayn KN. Fatty acids, obesity, and insulin resistance: time for a reevaluation. Diabetes. 2011;60(10):2441-2449.

26. Jelic K, Luzio SD, Dunseath G, Colding-Jorgsensen M, Owens DR A cross-sectional analysis of NEFA levels following standard mixed meal in a population of persons with newly diagnosed type 2 diabetes mellitus across a spectrum of glycemic control [Abstract]. Alexandria, VA: American Diabetes Association; 2007. Available from: http://professional.diabetes.org/Abstracts_Display.aspx?CID=54998. Accessed September 26, 2014.

27. Roden M, Price TB, Perseghin G, et al. Mechanism of free fatty acidinduced insulin resistance in humans. J Clin Invest. 1996;97(12): 2859-2865.

28. Fain JN, Madan AK, Hiler ML, Cheema P, Bahouth SW. Comparison of the release of adipokines by adipose tissue, adipose tissue matrix, and adipocytes from visceral and subcutaneous abdominal adipose tissues of obese humans. Endocrinology. 2004;145(5):2273-2282.

29. Marcial JM, Altieri PI, Banchs H, Escobales N, Crespo M. Metabolic syndrome among Puerto Ricans and other Hispanic populations P R Health Sci J. 2011;30(3):145-151.

30. Boden G. Fatty acids and insulin resistance. Diabetes Care. 1996;19(4): 394-395.

31. Kahn SE, Prigeon RL, McCulloch DK, et al. Quantification of the relationship between insulin sensitivity and beta-cell function in human subjects. Evidence for a hyperbolic function. Diabetes. 1993;42(11): 1663-1672.

32. Kahn SE. Clinical review 135: the importance of beta-cell failure in the development and progression of type 2 diabetes. J Clin Endocrinol Metab. 2001;86(9):4047-4058.

33. Wellen KE, Hotamisligil GS. Inflammation, stress, and diabetes. J Clin Invest. 2005;115(5):1111-1119.

34. Cnop M, Landchild MJ, Vidal J, et al. The concurrent accumulation of intra-abdominal and subcutaneous fat explains the association between insulin resistance and plasma leptin concentrations: distinct metabolic effects of two fat compartments. Diabetes. 2002;51(4):1005-1015.

35. Goran MI, Ball GD, Cruz ML. Obesity and risk of type 2 diabetes and cardiovascular disease in children and adolescents. J Clin Endocrinol Metab. 2003;88(4):1417-1427.

36. Bacha F, Saad R, Gungor N, Arslanian SA. Are obesity-related metabolic risk factors modulated by the degree of insulin resistance in adolescents? Diabetes Care. 2006;29(7):1599-1604.

\section{Publish your work in this journal}

Diabetes, Metabolic Syndrome and Obesity: Targets and Therapy is an international, peer-reviewed open-access journal committed to the rapid publication of the latest laboratory and clinical findings in the fields of diabetes, metabolic syndrome and obesity research. Original research, review, case reports, hypothesis formation, expert opinion and commentaries are all considered for publication. The manuscript management system is completely online and includes a very quick and fair peer-review system, which is all easy to use. Visit http://www.dovepress.com/testimonials.php to read real quotes from published authors. 